\title{
Euglycemic diabetic ketoacidosis associated with sodium-glucose cotransporter-2 inhibitor use: a case report and review of the literature
}

\author{
Alexis Diaz-Ramos ${ }^{1}$, Wesley Eilbert ${ }^{1 *}$ and Diego Marquez ${ }^{2}$
}

\begin{abstract}
Background: The sodium-glucose cotransporter-2 (SGLT2) inhibitors are the newest class of anti-hyperglycemic medications used in the treatment of diabetes mellitus. Their increasing use has been driven by their apparent cardiovascular and renal benefits. They have been associated with a small but significantly increased risk of diabetic ketoacidosis (DKA). Many of the cases of DKA associated with SGLT2 inhibitor use present with normal or minimally elevated serum glucose levels, often delaying the diagnosis.

Case presentation: A 44-year-old woman with diabetes mellitus presented to our emergency department complaining of 3 days of generalized weakness. The SGLT2 inhibitor canagliflozin had been added to her medication regimen 4 weeks earlier, and she had stopped using insulin 2 weeks prior to presentation. Laboratory evaluation revealed a metabolic acidosis with an elevated anion gap and the presence of serum acetone, despite a minimally elevated serum glucose of $163 \mathrm{mg} / \mathrm{dL}$. The patient was treated for euglycemic DKA with intravenous infusions of insulin and dextrose, with resolution of her symptoms in 3 days.

Conclusions: The SGLT2 inhibitors are a novel class of anti-hyperglycemic medications that are being used with increasing frequency in the treatment of diabetes mellitus. They are associated with a small but significantly increased risk of DKA. Many of the patients presenting with DKA associated with SGLT2 inhibitor use will have normal or minimally elevated serum glucose levels. This unusual presentation of DKA can be diagnostically challenging.

Keywords: Euglycemic diabetic ketoacidosis, Euglycemic DKA, Sodium-glucose cotransporter-2 inhibitor diabetic ketoacidosis, Sodium-glucose cotransporter-2 inhibitor euglycemic diabetic ketoacidosis, SGLT2 inhibitor DKA, SGLT2 inhibitor euglycemic DKA
\end{abstract}

\section{Background}

The American Diabetes Association has defined diabetic ketoacidosis (DKA) with the following diagnostic criteria: metabolic acidosis (arterial $\mathrm{pH}<7.3$ and sodium bicarbonate $<18 \mathrm{mmol} / \mathrm{L}$ ), ketosis (ketonemia or ketonuria), and hyperglycemia (serum glucose $>250 \mathrm{mg} / \mathrm{dL}$ ) [1]. In 1973, Munro et al. published the first case series of patients with DKA despite normal or minimally elevated serum glucose levels and describe the condition as euglycemic diabetic

\footnotetext{
*Correspondence: weilbert@uic.edu

'Department of Emergency Medicine, University of Illinois College of Medicine at Chicago, 1819 West Polk St. 469 COME, Chicago, IL 60612, USA Full list of author information is available at the end of the article
}

ketoacidosis (EDKA) [2]. Further investigations have revealed that up to $7 \%$ of reported DKA cases have a serum glucose less than $250 \mathrm{mg} / \mathrm{dL}$ [3]. Conditions associated with EDKA include pregnancy, heavy alcohol consumption, pancreatitis, decreased caloric intake, insulin pump use, chronic liver disease, and glycogen storage disorders [3, 4].

The sodium-glucose cotransporter-2 (SGLT2) inhibitors are a new class of anti-hyperglycemic medications first introduced in 2013 [5]. Canagliflozin, dapagliflozin, and empagliflozin are the most widely used medications in this class. These medications lower serum glucose levels by the novel mechanism of increasing glucose 
clearance in the urine, making them unlikely to cause hypoglycemia. Within 3 years of their use in global markets, both the US Food and Drug Administration (US FDA) and the European Medicines Agency issued warnings that SGLT2 inhibitor use may predispose to DKA $[6,7]$. Blau et al. reviewed the US FDA Adverse Event Reporting System regarding DKA associated with SGLT2 inhibitor use and found that $71 \%$ of the reported cases were EDKA [8].

In this report, we describe a case of EDKA associated with SGLT2 inhibitor use. Its pathophysiology, keys to diagnosis, and treatment will be discussed. Also, a review of the recent literature on this new, rare condition will be presented.

\section{Case presentation}

A 44-year-old Hispanic woman presented to our emergency department (ED) complaining of generalized weakness for the previous 3 days. She denied having associated fever, vomiting, diarrhea, or shortness of breath. She denied experiencing any pain. Her past medical history was remarkable for diabetes mellitus (DM), for which she was taking metformin $500 \mathrm{mg}$ twice daily, sitagliptin $100 \mathrm{mg}$ twice daily, and canagliflozin $100 \mathrm{mg}$ daily. The canagliflozin had been added to her medication regimen approximately 4 weeks earlier in the hopes of assisting her attempts to lose weight. The patient had been taking insulin as well up until 2 weeks before ED presentation, when it was discontinued by her endocrinologist who felt it was no longer needed for glycemic control.

On ED presentation, the patient was afebrile $\left(36.7^{\circ} \mathrm{C}\right)$, with a pulse rate of $79 \mathrm{bpm}$, blood pressure of $115 / 77$
$\mathrm{mmHg}$, and a respiratory rate of $18 \mathrm{bpm}$. She appeared well and in no distress. Her physical examination was notable for a normal neurologic exam including mental status, gait, and strength testing. Laboratory testing revealed a serum glucose of $163 \mathrm{mg} / \mathrm{dL}$, a low serum bicarbonate of $14 \mathrm{mmol} / \mathrm{L}$ (reference range $21-31 \mathrm{mmol} / \mathrm{L}$ ), and an elevated anion gap of $18 \mathrm{mmol} / \mathrm{L}$ (reference range $3.6-11.0 \mathrm{mmol} / \mathrm{L}$ ). The remainder of her serum electrolytes as well as her blood urea nitrogen and creatinine was within normal limits. A serum lactate level was within the range of normal. Ketones were present in the urine, and acetone was present in the serum. Venous blood gas analysis found a pH of 7.27 with a PCO2 of $29 \mathrm{~mm} / \mathrm{Hg}$.

After an initial bolus of intravenous (IV) $0.9 \%$ normal saline, the patient was started on a continuous IV infusion of insulin with a second infusion of $5 \%$ dextrose and sterile water added to prevent hypoglycemia. The patient was admitted to the intensive care unit for treatment of EDKA. All further doses of canagliflozin were withheld. On hospital day 3, the patient's ketosis and acidosis had resolved and she was discharged with insulin glargine, metformin, and sitagliptin for future control of her serum glucose levels.

\section{Discussion}

The SGLT2 inhibitors are currently recommended as second-line medications in the treatment of type $2 \mathrm{DM}$, though they may be used as the primary medication for this purpose [9]. They are also used off-label in the treatment of type $1 \mathrm{DM}[10]$. Their increasing use has been bolstered by recent studies that suggest they provide some protection against major adverse cardiovascular

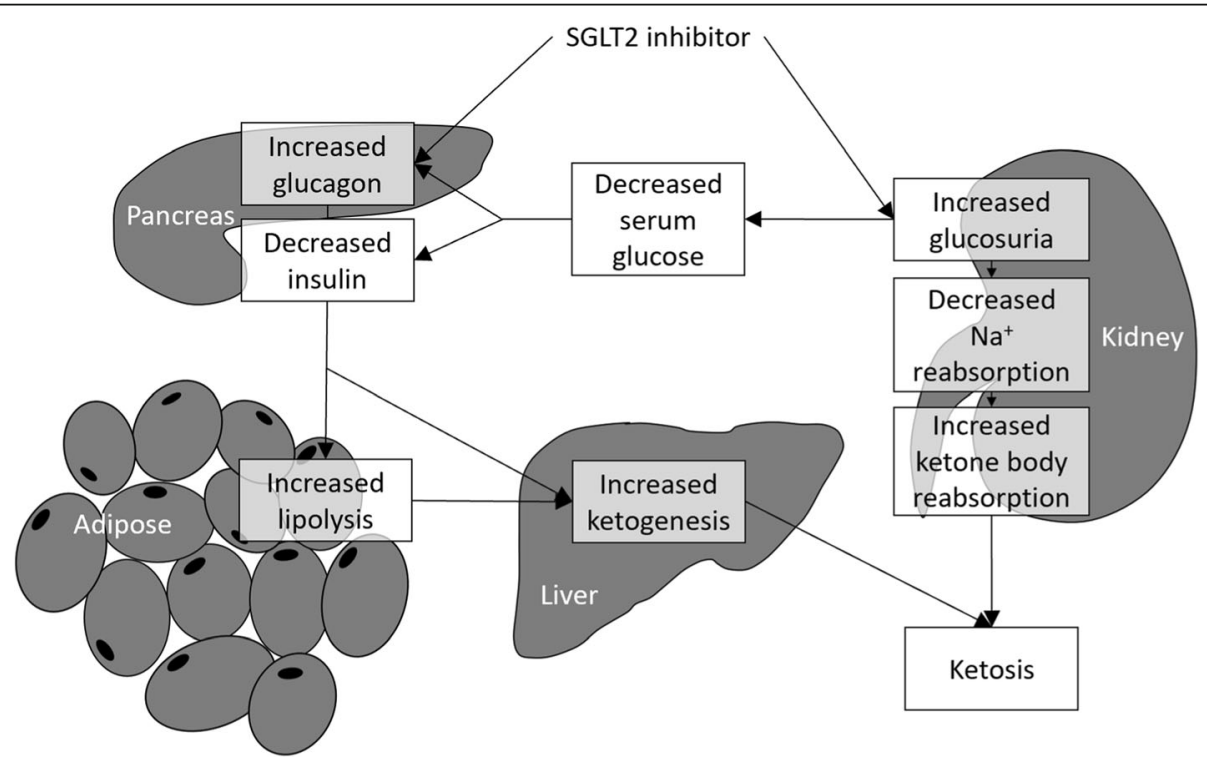

Fig. 1 The possible mechanism of euglycemic diabetic ketoacidosis caused by SGLT2 inhibitor use 
events and death, reduce hospitalization for heart failure, and slow the progression of chronic kidney disease in type 2 DM [11, 12]. They also appear to be associated with modest reductions in weight and systolic blood pressure [13].

The possible mechanisms by which SGLT2 inhibitors cause EDKA are illustrated in Fig. 1. SGLT2 inhibitors decrease serum glucose primarily by increasing glucosuria in the kidney. They also appear to directly stimulate release of glucagon from the pancreas [14]. The glucosuria leads to decreased sodium reabsorption in the kidney, which in turn leads to increased ketone body reabsorption. The glucosuria results in lower serum glucose values which decreases insulin release and increases glucagon release from the pancreas. The increased glucagon-to-insulin ratio results in increased lipolysis and fatty acid oxidation and ketone production by the liver.

DKA in the setting of SGLT2 inhibitor use occurs in patients with type $1 \mathrm{DM}$ with an incidence of 9.4\% [15]. It is much less common when used in type $2 \mathrm{DM}$, with an incidence less than $0.2 \%[16,17]$. Several small case series and meta-analyses have reported on the characteristics of DKA associated with SGLT2 inhibitor use [10, 17-24]. DKA occurring in the setting of SGLT2 inhibitor use typically presents with minimal hyperglycemia, resulting in a delay of the appropriate diagnosis in over $50 \%$ of cases [18]. Reported median glucose values in these cases range from 211 to $328 \mathrm{mg} / \mathrm{dL}$ [20, 22, 23].

As with our patient, most patients presenting with DKA while taking a SGLT2 inhibitor will do so within 2 months of starting the medication [18, 19, 23]. Most patients with DKA while taking a SGLT2 inhibitor will have a precipitating event, with dehydration, infection, surgery, and changes in insulin dose being commonly reported. Other reported precipitating factors are listed in Table 1 [18, 20-23]. Symptoms of DKA associated with SGLT2 inhibitor use are similar to DKA in general, with nausea, vomiting, and abdominal pain most commonly reported $[20,22]$. Patients with EDKA in particular may

Table 1 Common precipitants of diabetic ketoacidosis while taking a SGLT2 inhibitor

Vomiting

Dehydration

Discontinuation or reduction of insulin dose

Discontinuation of an oral insulin secretagogue

Surgery

Viral or bacterial infection

Fasting or reduction of caloric intake

Excessive ethanol use not manifest symptoms of dehydration to the degree of other DKA patients, given the lack of hyperglycemia [25, 26]. A recent US FDA review of adverse events associated with SGLT2 inhibitor use reported a fatality rate of $1.54 \%$, as compared with $0.4 \%$ for all DKA cases [19, 27].

EDKA associated with SGLT2 inhibitor use should be treated in a similar fashion as other types of DKA, but with consideration of the lack of hyperglycemia. Initial treatment is directed towards volume resuscitation with isotonic saline. The initial fluid replacement should be followed by continuous intravenous insulin infusion at a rate of $0.02-0.05$ units $/ \mathrm{kg} / \mathrm{h}$ [3]. Dextrose-containing fluids should be started along with the insulin infusion to avoid hypoglycemia, with a target serum glucose level of $150-200 \mathrm{mg} / \mathrm{dL}$. Serum electrolytes and glucose levels should be monitored closely during the treatment course. Resolution of EDKA is identified by the presence of two of the following: a serum bicarbonate level $\geq 15 \mathrm{mmol} / \mathrm{L}$, an anion gap $\leq 12 \mathrm{mmol} / \mathrm{L}$, or a venous $\mathrm{pH}>7.3$ [3].

\section{Conclusions}

The SGLT2 inhibitors are a new class of antihyperglycemic medications used in the treatment of DM. Their use has been associated with an increased risk of DKA. Many of the cases of DKA associated with SGLT2 inhibitor use will present with normal or minimally elevated serum glucose levels, and this frequently leads to a delay in diagnosis. The possibility of EDKA must be kept in mind when evaluating a patient with an unexplained metabolic acidosis while taking a SGLT2 inhibitor.

\section{Acknowledgments}

We are indebted to Joseph Eilbert for his assistance in the preparation of this manuscript.

\section{Authors' contributions}

ADR provided the information for the case report, performed the preliminary literature search, and assisted in the writing of the manuscript. WE performed the definitive literature search and assisted in the writing of the manuscript. DM assisted in the literature search and assisted in the writing the manuscript. All authors read and approved the final manuscript.

\section{Funding}

None.

\section{Availability of data and materials}

Data sharing is not applicable to this article as no data sets were generated or analyzed during the current study.

Ethics approval and consent to participate

Not applicable.

Consent for publication

Not applicable.

Competing interests

The authors declare that they have no competing interests. 


\section{Author details}

'Department of Emergency Medicine, University of Illinois College of Medicine at Chicago, 1819 West Polk St. 469 COME, Chicago, IL 60612, USA. 2University of Illinois College of Medicine at Chicago, 1853 West Polk St. MC 785, Chicago, IL 60612, USA.

Received: 11 July 2019 Accepted: 15 August 2019

Published online: 05 September 2019

\section{References}

1. Kitabachi AE, Umpierrez GE, Miles JM, Fisher JN. Hyperglycemic crisis in adults with diabetes. Diabetes Care. 2009;32:1335-43.

2. Munro JF, Campbell IW, McCuish AC, Duncan L. Euglycemic diabetic ketoacidosis. Br Med J. 1973;2:578-80.

3. Modi A, Agrawal A, Morgan F. Euglycemic ketoacidosis: a review. Curr Diabetes Rev. 2017;13(13):315-21.

4. Rawla P, Vellipuram AR, Bandaru SS, Predeep Raj J. Euglycemic diabetes ketoacidosis: a diagnostic and therapeutic dilemma. Endocrinol Diabetes Metab Case Rep. 2017. https://doi.org/10.1530/EDM-17-0081.

5. FDA news release. FDA approves Invokana to treat type 2 diabetes. https:// wayback.archive-it.org/7993/20170112023858/https:/www.fda.gov/ NewsEvents/Newsroom/PressAnnounce-ments/ucm345848.htm. Accessed 8 Mar 2019.

6. Drug safety announcement. FDA warns that SGLT2 inhibitors for diabetes may result in a serious condition of too much acid in the blood. https:// www.fda.gov/downloads/drugs/drugsafety/ucm446954.pdf. Accessed 10 Mar 2019.

7. EMA confirms recommendations to minimize ketoacidosis risk with SGLT2 inhibitors for diabetes. https://www.ema.europa.eu/en/medicines/human/ referrals/sglt2-inhibitors. Accessed 25 Feb 2019.

8. Blau JE, Tella SH, Taylor SI, Rother KI. Ketosis associated with SGLT2 inhibitor treatment: analysis of FAERS data. Diabetes Metab Res Rev. 2017;33. https:// doi.org/10.1002/dmrr.2924.

9. Garber AJ, Abrahamson MJ, Barzilay Jl, Blonde L, Bloomgarden ZT, Bush MA, et al. Consensus statement by the American Association of Clinical Endocrinologist and American College of Endocrinology on the comprehensive type 2 diabetes management algorithm - 2019 executive summary. Endocr Pract. 2019;25:69-100.

10. Goldenberg RM, Berard LD, Cheng AYY, Gilbert JD, Verma S, Woo VC, et al. SGLT2 inhibitor - associated diabetic ketoacidosis: clinical review and recommendations for prevention and diagnosis. Clin Ther. 2016;38:2654-64.

11. Zelniker TA, Wiviott SD, Raz I, Im K, Goodrich EL, Bonaca MP, et al. SGLT2 inhibitors for primary and secondary prevention of cardiovascular and renal outcomes in type 2 diabetes: a systematic review and meta-analysis of cardiovascular outcome trials. Lancet. 2019;393:31-9.

12. Wu JH, Foote C, Blomster J, Toyama T, Perkovic V, Sundstrom J, et al. Effects of sodium-glucose cotransporter-2 inhibitors on cardiovascular events, death, and major safety outcomes in adults with type 2 diabetes: a systematic review and meta-analysis. Lancet Diabetes Endocrinol. 2016:4:411-9.

13. Whalen $\mathrm{K}$, Miller $\mathrm{S}$, Onge ES. The role of sodium-glucose co-transporter 2 inhibitors in the treatment of type 2 diabetes. Clin Ther. 2015;37:1150-66.

14. Bonner C, Kerr-Conte J, Gmyr V, Queniat G, Moerman E, Thevenet J, et al. Inhibition of glucose transporter SGLT2 with dapagliflozin in pancreatic alpha cells triggers glucagon secretion. Nat Med. 2015;21:512-7.

15. Henry RR, Thakkar P, Tong C, Polidori D, Alba M. Efficacy and safety of canagliflozin, a sodium-glucose cotransporter 2 inhibitor, as add-on to insulin in patients with type I diabetes. Diabetes Care. 2015;38:2258-65.

16. Zinman B, Wanner C, Lachin JM, Fitchett D, Bluhmki E, Hantel S, et al. Empagliflozin, cardiovascular outcomes, and mortality in type 2 diabetes. N Engl J Med. 2015;373:2117-28.

17. Erondu N, Desai M, Ways K, Meininger G. Diabetic ketoacidosis and related events in the canagliflozin type 2 diabetes clinical program. Diabetes Care. 2015;38:1680-6.

18. Dizon S, Keely EJ, Malcolm J, Arnaout A. Insights into the recognition and management of SGLT2-inhibitor-associated ketoacidosis: it's not just euglycemic diabetic ketoacidosis. Can J Diabetes. 2017:41:499-503.

19. Fadini GP, Bonora BM, Avogaro A. SGLT2 inhibitors and diabetic ketoacidosis: data from the FDA adverse event reporting system. Diabetologia. 2017;60:1385-9.
20. Misaghian-Xanthos N, Shariff Al, Mekala K, Fearrington LR, Setji TL, Aloi JA, et al. Sodium-glucose transporter 2 inhibitors and diabetic ketoacidosis: a case series from three academic institutions. Diabetes Care. 2017:40:e65-6.

21. Handelsman Y, Henry RR, Bloomgarden ZT, Dagogo-Jack S, Defronzo RA, Einhorn D, et al. American Association of Clinical Endocrinologists and American College of Endocrinology position paper on the association of SGLT-2 inhibitors and diabetic ketoacidosis. Endocr Pract. 2016;22:753-62.

22. Burke KR, Schumacher CA, Harpe SE. SGLT2 inhibitors: a systematic review of diabetic ketoacidosis and related risk factors in the primary literature. Pharmacotherapy. 2017;37:187-94.

23. Drug safety communications. FDA revises labels of SGLT2 inhibitors for diabetes to include warnings about too much acid in the blood and serious urinary tract infections. https://www.fda.gov/downloads/drugs/drugsafety/ ucm475487.pdf. Accessed 14 Mar 2019.

24. Peters AL, Buschur EO, Buse JB, Cohan P. Diner JC, Hirsh IB. Euglycemic diabetic ketoacidosis: a potential complication of treatment with sodiumglucose cotransporter 2 inhibition. Diabetes Care. 2015;38:1687-93.

25. Ogawa W, Sakaguchi K. Euglycemic diabetic ketoacidosis induced by SGLT2 inhibitors: possible mechanism and contributing factors. J Diabetes Investig. 2016;7:135-8.

26. Jenkins D, Close CF, Krentz AJ, Nattrass M, Wright AD. Euglycemic diabetic ketoacidosis: does it exist? Acta Diabetol. 1993;30:251-3.

27. Benoit SR, Zhang Y, Giess LS, Gregg EW, Albright A. Trends in diabetic ketoacidosis hospitalizations and in-house mortality - United States, 2000-2014. MMWR Morb Mortal Wkly Rep. 2018;67:362-5.

\section{Publisher's Note}

Springer Nature remains neutral with regard to jurisdictional claims in published maps and institutional affiliations.
Ready to submit your research? Choose BMC and benefit from:

- fast, convenient online submission

- thorough peer review by experienced researchers in your field

- rapid publication on acceptance

- support for research data, including large and complex data types

- gold Open Access which fosters wider collaboration and increased citations

- maximum visibility for your research: over $100 \mathrm{M}$ website views per year

At BMC, research is always in progress.

Learn more biomedcentral.com/submissions 